\title{
Alignment of School and Leadership Practices in Basic Education with Response-to-Intervention Model
}

\author{
Maria Judith R. Raagas
}

\section{ABSTRACT}

This study assessed the implementation of school and leadership practices of the selected basic education schools and their alignment with the Responseto-Intervention (RTI) model components which enhanced the RTI implementation. The gaps in aligning the school and leadership practices with the RTI model were identified as concerns. As the RTI model is about preparing all students for success in their adult lives and careers, the school leaders hold a very significant position in improving the academic performance of all their learners. The study used the mixed method. The quantitative data analysis used a survey questionnaire and sent to the respondents through Google Forms. The descriptive statistics of frequency, mean and standard deviation was calculated using the IBM SPSS Statistics. For the qualitative data, an interview was conducted with the school principals, guidance counselors and selected class advisers, to clarify and support the responses in the survey questionnaire.

Based on the findings, the researcher designed the contextualized RTI framework for basic education in Cebu City, Philippines. The recommendations of the study were: (1) include the RTI systems and procedures in the quality management system of the school; (2) for human resource departments and hiring committees, they should consider the qualification each potential new principal his or her previous experience working with students with special needs; (3) schools should consider providing professional development and training opportunities to principals whose sole or primary classroom teaching experience has been in general education; and, (4) for an individualized professional development planning process, principals might want to incorporate professional development opportunities that focus on leadership support for interventions.

Keywords: leadership practices, response-to-intervention, school practices, student at-risk.

\section{INTRODUCTION}

The UNESCO's International Forum on Inclusion and Equity in Education held in Cali, Colombia on September 11-13, 2019, commemorated the $25^{\text {th }}$ anniversary of the World Conference on Special Needs Education in Salamanca, Spain in 1994. The forum looked at the challenges and strategies that overcome the obstacles for vulnerable and marginalized groups and celebrated the progress in moving towards the system in educations that no one is left behind as promoted by the 2030 Agenda for Sustainable Development. The international forum calls for "all children and young people should learn together, wherever possible, regardless of any difficulties or differences they may have. Inclusive schools and learning settings must recognize and respond to the diverse needs of their students" [1].

Since the endorsement of Inclusive Education by UNESCO, the academes of the member nations worldwide
Published Online: July 28, 2021

ISSN: $2736-4534$

DOI :10.24018/ejedu.2021.2.3.144

Maria Judith R. Raagas*

CIE British School, Cebu City, Philippines.

(e-mail: mariajudithraagas4@gmail.com)

*Corresponding Author recognized that inclusive education implementation as an optimistic progress in education. But these academes recognized the underlying concern, that inclusive education posed a great challenge to the stakeholders. In this context, the domain of educational leadership is fast changing to meet the different academic and behavioral difficulties of all students.

In support to inclusive education, the United States passed the Individuals with Disabilities Education Act (IDEA) in 2004 which guarantee the education rights for children ensuring that they are educated with their peers in the general education classroom as much as possible based on their ability and needs. IDEA reflected new ideas about learning disabilities and the concept of a pre-determined strategy was called response to intervention or RTI. Finland followed and the other countries in Europe. Response to Intervention (RTI) was a new framework recognized in United States and in Europe, in the later part of 1990s, for identifying learning difficulties of students. In the recent study, the RTI 
framework is presented from the perspective of the role of assessment and instruction as provided in documents that describe the frameworks [2].

The Philippines Enhanced Basic Education Act of 2013 mandates an education that is "learner-oriented and responsive to the needs, cognitive and cultural capacity, the circumstances and diversity of learners." However, in the Philippine Education for All 2015 Review Report to UNESCO, the situation of the implementation of Education for All (EFA) in the Philippines is that there are hindrances in achieving the indicators that mandates the focus on disparities and inequalities that blocks EFA. One of this is the understanding that inclusive education pertains to institutionalization of programs for the marginalized children, not on children with disabilities [3].

This study came from the fact that there is a limited sound practice of inclusive education (IE) in the Philippines. The lack of shared education approach in our country implies that there is a need to establish an effective inclusive education practice. This limitation is a challenge to enunciate on how the school community be involved in the education of children with disabilities. How should a school make inclusive education effective, what model should a school consider and what are the requirements that must be complied with, are the concerns that remain unsolved by school administrators. The study is about response-tointervention (RTI), a system that relates to inclusive education, specifically, it aids in an early detection of learners with disabilities, provide academic support and intervention based upon the individual needs of the learners. The school and leadership practices of the selected schools are assessed whether these are aligned to the RTI model under study.

This study assessed the implementation of the school and leadership practices of the selected basic education schools and their alignment with the response-to-intervention model.

Specifically, the study answered the following questions:

1. What are the school practices in relation to:

1.1 admission requirements;

1.2 assessment;

1.3 program options;

1.4 progress and monitoring; and,

1.5 support services?

2. How are these practices aligned with the following response-to-intervention model components?

2.1 universal screening;

2.2 formative assessment;

2.3 progress monitoring;

2.4 cut points; and,

2.5 evidence-based intervention?

3. How are the leadership practices aligned with the implementation of the response-to-intervention model in terms of:
3.1 direction;
3.2 vision;
3.3 challenges;
3.4 support; and,
3.5 motivation?

4. What are the concerns in the implementation of the practices and its alignment to response-to-intervention model?
5. How may a response-to-intervention framework be designed for an enhanced implementation of RTI?

\section{MEthodS}

This study used the mixed method of research. The mixed method involved the collection of both qualitative (openended) and quantitative (closed-ended) data in response to research questions or hypothesis [4].

In this study, the researcher gathered the quantitative and qualitative data, and these data were analyzed separately and determine if the results of the analysis support each other. The expectation was that the qualitative and the quantitative data resulted to distinct types of information and the viewpoints of the respondents and the ratings on the quantitative instruments are expected to yield results that are similar, if not the same. The researcher analyzed and evaluated the two data gathered through the procedure of integrating the results of the quantitative and qualitative data gathered and used these results in the design of the RTI contextualized framework.

The mixed method utilized a survey instrument and semistructured interview. The online survey was drafted using Google Forms. The survey questionnaire in Google Forms was emailed with an introductory message to the participants introducing the research purposes and inviting them to participate in the survey.

The approach in the qualitative methods is phenomenology. Phenomenology focused on the experiences of the participants of study, their lived experiences. To be able to get the underlying principles of the meaning of an experience, the researcher used a phenomenological interview as the primary method of collecting data [5].

Before interviewing the participants on their experiences, the researcher also explored her own experiences, to examine the dimensions of the experience and to become aware of personal biases and notions.

In this study, the quantitative data were collected through a survey questionnaire, then follow-up interviews that clarified or supported the responses to the questions.

The qualitative data is built on the first stage of quantitative research and these two stages were integrated in the data analysis. Within the mixed method design, the qualitative data was used to explain the quantitative or numeric data through an in-depth exploration of participants' views [5].

\section{RESULTS}

The result of the study is that the school administrators, teachers, and staff of the public and private schools did not have considerable knowledge of RTI system. This included a range of aspects of the RTI model. The school administrators at some extent understood the basic components of RTI, like formative assessment, cut points and progress monitoring, as these are aligned with their respective school practices. They lacked understanding though on universal screening and evidence-based intervention. Generally, the participants were unable to 
correctly explain response-to-intervention and their knowledge was limited to a shallow understanding of the other components. In general, the respondents lacked a comprehensive understanding of the model itself or the way each RTI components function within a systematic approach.

\section{DISCUSSIONS}

\section{A. School Practices}

The results on school practices showed that in public schools, the schools' practices such as admission requirements, assessment, program options and support services are implemented at some extent. Public schools always follow the directives of the Schools City Division as cascaded from the Department of Education Central Office. This became apparent specifically in admission requirements which is mandated by DepEd Orders No. 3, s. 2018 and No. 8, s. 2020. They admit all students without any screening as long as the students can submit the documentary requirements. Assessment is also practiced following the standards prescribed in DepEd Orders No. 8, s. 2015 and No. 31, s. 2020. In program options, though DepEd Order No. 72, s. 2009 provided two options for public schools to choose from, majority of the public schools opted for the first option which is a self-contained class for children with similar special needs. This is supported by the study of Mcmillan [6] on the benefits and obstacle of inclusive education, that the environment in this program option is structured, routine and with some expectations. The self-contained program though socially and academically restrictive may be an ideal model for the delivery of special services that are required based on the individual needs of the students [6].

The private school respondents' results in school practices showed that these are implemented to a moderate extent. With the international accreditations that they have to follow, their school policies strictly abide with the accreditations. Most of the school practices are implemented by the private schools in great extent. However, their program option is similar to the public schools, they also opted for a self-contained class for children with similar special needs.

\section{B. Alignment of School Practices with RTI Model}

On the alignment of school practices and RTI model, the researcher aligned the school practices and the RTI model components by matching the similarities of the elements of the practices with the elements of the RTI components. The school practices of admission requirements were aligned with universal screening, assessment was aligned with formative assessment and cut points, progress monitoring is with progress monitoring and the support services was aligned with evidence-based intervention as this is a service that is provided in the RTI system.

The RTI model in this study is based on the RTI components prescribed by the National Center for Responseto-Intervention of the American Institute for Research. The result showed that there is no alignment with the program options practice of the schools in the RTI components since RTI completely relates to inclusive education, which is basically option 2 in DepEd Order No. 79, s. 2009. In the RTI system, all students are included in regular classes, regardless of their disabilities.

To have an in-depth analysis of the alignment, the researcher surveyed the extent of implementation of the RTI components. The results showed that in the admission requirements, the universal screening is not being implemented by both the public and private schools. Though, the private schools showed a moderate extent of implementation of universal screening, they were referring to the placement tests and interview that they administer to the student applicants, which is totally different from the RTI universal screening. This finding is supported by the responses to the interview of the respondents.

\section{Alignment of Leadership Practices with RTI Model}

On the alignment of leadership practices and RTI model, the purpose of the alignment was for the researcher to gain insights that could be useful for school administrators in the implementation process of RTI. It also determines the teachers' and staff's attitude towards their school administrators that is crucial in the effective implementation of the RTI system. It is necessary to align the leadership practices of school administrators because the successful implementation of the RTI system requires them to take a new, unfamiliar roles in the school.

The alignment of leadership practices with RTI model is different from the alignment of the school practices with RTI model. The researcher considered the extent to which these practices is implemented by the school administrators which is necessary for the effective implementation of the RTI system.

The results showed that the leadership practices in public schools is implemented only at some extent and in private school these practices are implemented at moderate extent. The result in public schools is supported in the study of Lembke, et. al., on school administrators' participation in the RTI process, four elements were identified that became the barrier for the effective implementation of leadership practices in participating in the RTI process: the direction and vision of the administrators is not clear to the teachers and staff which failed to elicit commitment on the part of the administrators, unable to initiate new approaches or ways that lead to the achievement of goals and objectives of the school, failure to continually motivate and collaborate with the teaching and non-teaching staff. If the school administrators eliminate these barriers, then the school will be successful in meeting the needs of all students, thus RTI implementation becomes effective [7].

\section{Concerns in the Implementation of the Practices and its alignment of $R T I$}

The concerns in the implementation of the practices and its alignment with RTI were based on the result of the analysis of the responses of the research participants. The survey and interview responses resulted to three main concerns identified by the researcher as: limited understanding of response-to-intervention system as an aid to inclusive education; the leadership practices of the publicschool administrators may break down the new system being introduce and limited administrative support. 
Limited Understanding of RTI Systems. One of the major drawbacks was that the 319 respondents have limited understanding of the RTI components. While most of the respondents were able to identify the different assessments that were used in the schools, they generally lacked understanding of the processes of RTI specifically on universal screening and evidence-based intervention.

Leadership Practices of School Administrators. The second significant concern is that leadership practices of school administrators are only implemented at some and moderate extent. RTI system needs great extent of implementation of RTI to have a conformity of implementation within the school sites. Educational leadership is an important factor to this study. It is always a key ingredient for the success of response-to-intervention implementation [8]. Schools are successful because of the high quality of leadership which provides supports to students and staff. Educational leaders have a wider scope of responsibilities not only budgeting, procurement, provision, and improvement of school facilities but also to student behavior and community relations [9].

Limited Administrative Support. For the public-school respondents, they have some concerns on administrative support. They are very keen on financial resources and that for any new programs that are introduced to them needs financial support. This will be true especially in the frequent and consistent implementation of universal screening and progress monitoring for the students.

With the private schools, the administrative support given by the administrators is at moderate extent. The private schools can easily seek administrative support from the administrators, specifically financial support. What they need as support from administration is the professional development and training in RTI.

Administrative support is an important factor for the successful implementation of RTI. It is the responsibility of school administrators as leaders to define the roles and responsibilities of the staff, develop and implement school policies and to consider using time and resources carefully when managing educational programs [10].

\section{E. The Output of the Study}

The output of this study is the contextualized response-tointervention framework developed for the success of educating students in the City of Cebu, Philippines. To achieve this goal, the researcher developed the framework with a 3-phased system of support. The RTI Framework is a three-phased system model that provides a three-level structure of support where the support given to the students increases its strength depending on the needs of the learners. The framework was based on the concern on limited understanding of the RTI model concept, practices, or processes. The phases in the framework are also procedures on how the RTI will be effectively implemented. The framework includes the five (5) RTI components: universal screening, formative assessment, progress monitoring, cut points and evidenced-based intervention. The contextualized RTI framework is expected to result in effective academic, behavioral, and mental wellness instructions and interventions for all students in the community.

\section{CONCLUSION}

The study concluded that the key to effective implementation of the response-to-intervention are the moderate or great extent implementation of school and leadership practices of school administrators. The study showed that the school principal as administrator is at the center of managing initiatives and reforms, and this study concludes that school leadership practices lead to student achievement. Additionally, education reform initiatives, such as RTI may not necessarily lead to improved results but focus and the ability to sustain an effective practice over time can lead to improve results for students. Finally, people make systems function during change. A system that provides great extent of leadership practices paves way for a successful reform.

The study further concludes that RTI cannot be categorized as one educational program, but a transformation in the way the school administrators operate and manage their schools. The essential to success of this initiatives is for school leaders to understand and embrace the process of change and how to manage it. The study and its literature review sufficiently identify factors that contribute to the successful implementation of RTI. It is part of the continuous pursuit to improve school systems and school personnel, understanding the process of change is important for educational administrators to successfully implement RTI. Success is described by Fullan [11] as a hierarchy of successive level, that is, students cannot be successful without successful teachers; teachers cannot be successful without successful leaders; and leaders must sustain the betterment of all stakeholders through sustaining meaningful educational change.

School administrators, especially principals are seen as having the ability to develop supportive educational environments for the implementation of RTI. Effective leaders help organizations and staff through inspiring, guiding, goals setting, conflict resolution and resource allocation. A critical component to the effective implementation of RTI is the establishment of collaborative teams at all levels. The leader is responsible for creating the environment to guide staff into the practice of collective inquiry, the practice of using data to make decisions and engaging the staff to willingly participate in professional development are all essential aspects of an effective RTI system.

This lack of administrative support was felt by the researcher during the school visits. The school administrators believed that there is a need to support in all educational projects, but it is always that support is hold up by an administrative decision. Generally, school administrators believed that RTI as a new system needs financial resources. Resources is needed to support the frequent and consistent implementation of universal screeners and progress monitoring tools for the students. When students move from one school to another school in the locality, it may be a challenge to measure and do progress monitoring as there will always be inconsistency. It is difficult to compare student performance every time a student moves, and the assessment measures themselves change. This inconsistency makes the decisions making particularly challenging. One administrator did share that it 
is her hope that RTI will be used effectively as a tool to remediate student difficulties, before determining that the student has a disability. It is the only way that the students with learning difficulties can easily be moved to the mainstream of the society.

\section{REFERENCES}

[1] UNESCO Education Sector, "Final Report: International forum on inclusion and equity in education," UNESCO, Paris, 2019.

[2] P. M. Björn, M. Aro, T. Koponen, L. S. Fuchs and D. Fuchs, "Response-To-Intervention in Finland and the United States: Mathematics Learning Support as an Example," Frontiers in Psychology, 2018.

[3] Department of Education, "The Philippine Education for All 2015 Review Report," UNESCO, Paris, 2015.

[4] J. Creswell and C. Poth, Qualitative Inquiry and Research Design: Choosing Among Five Approaches, 4th Edition, Thousand Oaks, California: Sage Publications, 2017.

[5] J. Creswell, Research Designs: Qualitative, Quantitative and MIxed Methods Approaches, Thousand Oaks, California: Sage Publication, Inc., 2014.

[6] N. McMillan, "Inclusive Education: The Benefits and Obstacle," Digital Commons@Brockport, pp. 39 - 42, 2018.

[7] E. Lembke, C. Garman, S. Deno and P. Stecker, "One Elementary School's Implementation of Response to Intervention (RTI)," Reading and Writing Quarterly, pp. 361-373, 2015.

[8] R. Bean and J. Lillenstein, "Response to Intervention and the Changing Roles of Schoolwide Personnel," The Reading Teacher, pp. 491-501, 2016
[9] T. Yeigh, D. Lynch, D. Turner, S. Provost, R. Smith and R. Willis, "School leadership and school improvement: an examination of school readiness factors," School Leadership \& Management, pp. 434-456, 2019.

[10] E. O'Connor and F. Elizabeth, "District-level considerations in supporting and sustaining RtI implementation," Psychology in the Schools, pp. 297-310, 2012.

[11] M. Fullan, "Leadership from the Middle," Education Canada, pp. 2226, 2015.

[12] K. Leithwood, A. Harris and D. Hopkins, "Seven Strong Claims about Successful School Leadership Revisited," School Leadership and Management, pp. 1-18, 2019.

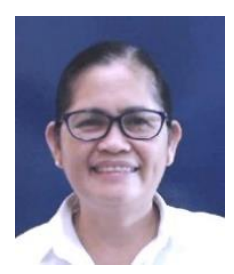

Dr. Maria Judith R. Raagas is the Senior Vice President and Dean of Colleges of CIE British School in Cebu City, Cebu, the Philippines. A Doctor of Philosophy in Education major in Educational Administration at the University of San Carlos, Cebu City, Philippines in 2021 and obtained her Doctor in Management degree at the University of San Jose-Recoletos, Cebu City, the Philippines in 1998. She also earned her Doctor Juris degree at Xavier University, Cagayan de Oro City, Philippines in 1985.

Her research inclination is on internationalization of higher education and inclusive education in the Philippines. She attended numerous seminars and trainings in Singapore, Hongkong, Dubai and United Kingdom. She also presented research paper during the Inclusive Education convention in New York, New York, USA last November 8 13, 2019. Dr. Raagas also published some research articles about internationalization and inclusive education in international refereed journals. 